\title{
Selenoesters and Selenoanhydrides as Novel Agents Against Resistant Breast Cancer
}

\author{
ANDREA CSONKA ${ }^{1,2}$, ANNAMÁRIA KINCSES ${ }^{1}$, MÁRTA NOVÉ ${ }^{1}$, ZSÓFIA VADAS ${ }^{1}$, \\ CARMEN SANMARTÍN ${ }^{3,4}$, ENRIQUE DOMÍNGUEZ-ÁLVAREZ ${ }^{5}$ and GABRIELLA SPENGLER ${ }^{1}$ \\ ${ }^{1}$ Department of Medical Microbiology and Immunobiology, \\ Faculty of Medicine, University of Szeged, Szeged, Hungary; \\ ${ }^{2}$ Department of Obstetrics and Gynecology, Faculty of Medicine, University of Szeged, Szeged, Hungary; \\ ${ }^{3}$ Department of Pharmaceutical Technology and Chemistry, \\ School of Pharmacy and Nutrition, University of Navarra, Pamplona, Spain; \\ ${ }^{4}$ Institute of Health Research of Navarra (IdiSNA), Pamplona, Spain; \\ ${ }^{5}$ Institute of General Organic Chemistry, Spanish National Research Council (IQOG-CSIC), Madrid, Spain
}

\begin{abstract}
Background/Aim: Selenium-containing compounds are becoming new alternatives in experimental chemotherapy in order to overcome multidrug resistance in cancer. The main goal of this study was to determine whether combined treatment with new Se-compounds would increase the effect of conventional doxorubicin chemotherapy in breast cancer cell lines. Materials and Methods: Se-compounds were evaluated regarding their cytotoxic and apoptosis-inducing effect on $M C F-7$ and ATP-binding cassette subfamily $B$ member 1 (ABCB1)-overexpressing KCR breast cancer cell lines. Moreover, the interaction of Se-compounds with doxorubicin was assessed using the MTT assay. Results: Selenoanhydride exerted a selective activity towards the doxorubicin-resistant $K C R$ cell line overexpressing ABCB1. Among the selenoesters, only ketone-containing selenoesters exerted significant cytotoxic activity against MCF-7 and KCR cell lines and the Se-compounds acted synergistically with doxorubicin on the $\mathrm{KCR}$ cell line. Conclusion: The importance of the $\mathrm{COSeCH}_{2} \mathrm{COCH}_{3}$ and $\mathrm{COSeCH}_{2} \mathrm{CO}\left(\mathrm{CH}_{3}\right)_{3}$ moieties for the cytotoxic and adjuvant role of Se-compounds was highlighted.
\end{abstract}

Selenium-containing compounds (Se-compounds) are becoming a novel and promising alternative approach in the fight against cancer: according to recent reviews in the

Correspondence to: Gabriella Spengler, Department of Medical Microbiology and Immunobiology, Faculty of Medicine, University of Szeged, Dóm tér 10, H-6720 Szeged, Hungary. Tel: +36 62545115, Fax: +36 62545113, e-mail: spengler.gabriella@med.uszeged.hu

Key Words: Selenoesters, apoptosis, breast cancer, ABCB1 (P-glycoprotein), doxorubicin. field, many selenium derivatives have been reported to show antiproliferative, anticancer or cancerchemopreventive activity in different biological assays (1, 2 ). The mechanisms of action of the Se-compounds against cancer are very diverse, as these derivatives can interact with key biological processes such as oxidative stress, angiogenesis, and apoptosis induction, among others $(1,2)$. Furthermore they possess chemopreventive properties (3, 4). Besides their intrinsic anticancer activity, specific selenium derivatives can inhibit certain cancer resistance mechanisms such as the function of multidrug resistance (MDR) efflux pumps $(5,6)$, or can modulate the activity of chemotherapeutic drugs $(7,8)$.

Previously our group synthesized a selenoanhydride and a series of selenoesters (Figure 1), finding that they were potent antiproliferative and anticancer agents (9). Subsequently, four of these selenium derivatives (selenoanhydride $\mathbf{1}$ and the ketone-containing selenoesters $\mathbf{9 -}$ 11) were described as very potent inhibitors of the ATPbinding cassette subfamily $B$ member 1 (ABCB1; P-glycoprotein) efflux pump in the MDR subline of the mouse T-lymphoma cell line L5178Y (5) and in MDR Colo 320 colon adenocarcinoma cell line (6). In addition, they interacted synergistically with chemotherapeutic drugs such as vincristine, doxorubicin, cyclophosphamide, methotrexate, topotecan and 5-fluorouracil in checkerboard combination assay on L5178Y mouse T-lymphoma cells (10).

It has been reported that Se-compounds are less active against MCF-7 cells compared to other tumor cell lines such as A549, PC-3 and HT-29 (9). Herein, we aimed to determine whether combined treatment with Se-compounds and doxorubicin would overcome this previously observed resistance, and become thus a novel and promising approach to fight breast cancer. 


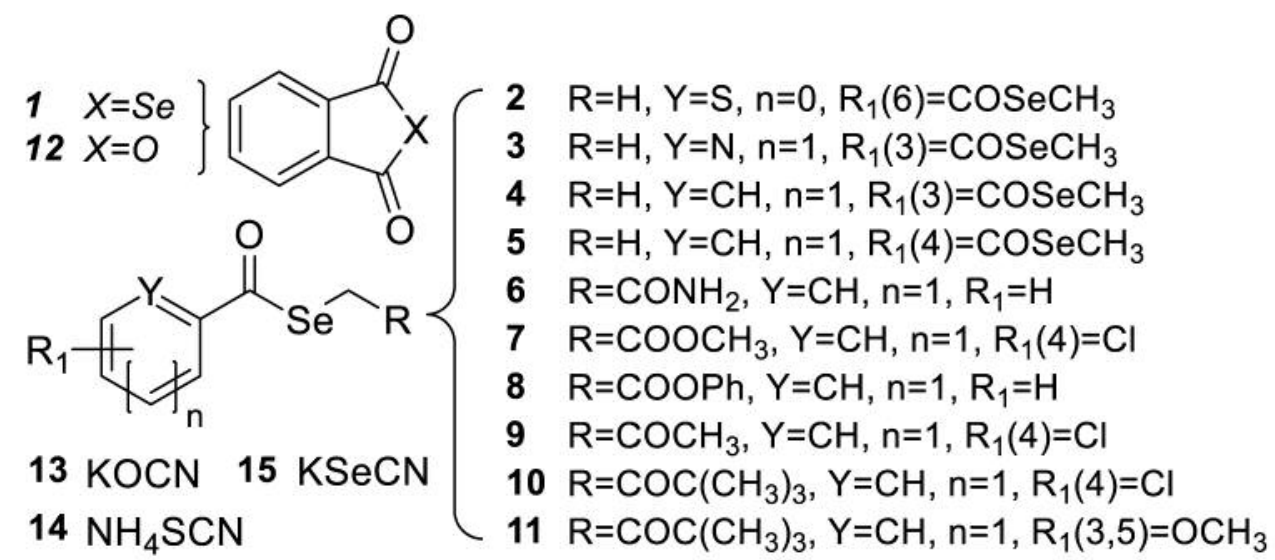

Figure 1. Chemical structure of the tested compounds. The number in parentheses denotes the position at which $R_{1}$ is bound to the (hetero) aromatic ring.

\section{Materials and Methods}

Compounds. The eleven Se-compounds tested (selenoanhydride $\mathbf{1}$ and selenoesters 2-11, Figure 1) were kindly provided by Dr. Enrique Domínguez-Álvarez (Spanish National Research Council, Madrid, Spain) and by Professor Dr. Carmen Sanmartín (University of Navarra) (9). Se-compounds 1-11 were stable and their purity was assessed through spectroscopic techniques (elemental analysis, nuclear magnetic resonance, mass spectrometry and infrared spectroscopy). Compounds 12-15 were purchased from Sigma-Aldrich (Steinheim, Germany), respectively, to be used as non-selenium (12) isostere of selenoanhydride (1) and as inorganic chalcogen salts (13-15), for comparing their activity with the selenoesters. The compounds were dissolved in dimethyl sulfoxide (DMSO).

Cell lines. Breast cancer cell line MCF-7 (ATCC ${ }^{\circledR}$ HTB-22) was purchased from LGC Promochem (Teddington, Middlesex, UK). The MCF-7 cell line and its drug-resistant subline KCR were grown in Eagle's minimal Essential medium (EMEM), containing $4.5 \mathrm{~g} / \mathrm{l}$ glucose supplemented with a non-essential amino acid mixture, a selection of vitamins and $10 \%$ heat-inactivated fetal bovine serum. The cell lines were incubated at $37^{\circ} \mathrm{C}$, in an atmosphere of $5 \% \mathrm{CO}_{2}$ and $95 \%$ air. On every third passage, $0.56 \mu \mathrm{g} / \mathrm{ml}$ doxorubicin (Teva Pharmaceuticals, Budapest, Hungary) was added to the medium in order to maintain $\mathrm{ABCB} 1$ expression in KCR cells.

Cytotoxicity assay. The cytotoxic effects of the Se-compounds were determined on MCF-7 and KCR breast cancer cell lines. The effects of increasing concentrations of Se-compounds on cell growth were tested in 96-well flat-bottomed microtiter plates. The compounds were diluted in $100 \mu \mathrm{l}$ of medium.

The adherent breast cancer cell lines were cultured in 96-well flat-bottomed microtiter plates, using EMEM supplemented with $10 \%$ heat-inactivated fetal bovine serum. The density of the cells was adjusted to $1 \times 10^{4}$ cells in $100 \mu \mathrm{l}$ per well, the cells were seeded for $24 \mathrm{~h}$ at $37^{\circ} \mathrm{C}$, with $5 \% \mathrm{CO}_{2}$ prior to the assay, then the medium was removed from the plates containing the cells, and dilutions of Se-compounds were previously made in a separate plate and added to the cells in $200 \mu \mathrm{l}$.
The culture plates were incubated at $37^{\circ} \mathrm{C}$ for $24 \mathrm{~h}$; at the end of the incubation period, $20 \mu \mathrm{l}$ of thiazolyl blue tetrazolium bromide (MTT; Sigma) solution (from a stock solution of $5 \mathrm{mg} / \mathrm{ml}$ ) were added to each well. After incubation at $37^{\circ} \mathrm{C}$ for $4 \mathrm{~h}, 100 \mu \mathrm{I}$ of sodium dodecyl sulfate (Sigma) solution (10\% in $0.01 \mathrm{M} \mathrm{HCI}$ ) were added to each well and the plates were further incubated at $37^{\circ} \mathrm{C}$ overnight. Cell growth was determined by measuring the optical density (OD) at 540/630 nm with Multiscan EX ELISA reader (Thermo Labsystems, Cheshire, WA, USA). Inhibition of the cell growth was determined according to the formula below:

$$
\mathrm{IC}_{50}=100-\left[\frac{\text { OD sample }-O D \text { medium control }}{\text { OD cell control }- \text { OD medium control }}\right] \times 100
$$

Results are expressed in terms of $\mathrm{IC}_{50}$, defined as the inhibitory dose that reduced the growth of the cells exposed to the tested compounds by $50 \%$.

The selectivity was calculated using the selectivity index (SI), which is defined as the quotient of the $\mathrm{IC}_{50}$ value determined for the non-tumorous MRC-5 cell line described previously (6) to the $\mathrm{IC}_{50}$ value for the respective cancer cell line (MCF-7 or KCR). Following the criteria reported in bibliography (6), we considered a compound to be strongly selective when its SI was 6 or higher. Compounds with SI values of 1-3 and 3-6 were regarded as slightly and moderately selective, respectively.

Checkerboard combination assay. A checkerboard microplate method was applied to study the effect of drug interactions between the Se-compounds 1-11 and the chemotherapeutic drug doxorubicin. The assay was carried out on MCF-7 and KCR breast cancer cell lines. The adherent breast cancer cell lines were cultured in 96-well flat-bottomed microtiter plates, using EMEM supplemented with $10 \%$ heat-inactivated fetal bovine serum. The density of the cells was adjusted to $6 \times 10^{3}$ cells in $100 \mu \mathrm{l}$ per well, the cells were seeded for $24 \mathrm{~h}$ at $37^{\circ} \mathrm{C}$ with $5 \% \mathrm{CO}_{2}$ prior to the assay and then the medium was removed from the plates containing the cells.

The final concentration of the Se-compounds and doxorubicin used in the combination experiment was chosen in accordance with 


\section{Compound}

Doxorubicin concentration

Se-compound

concentration

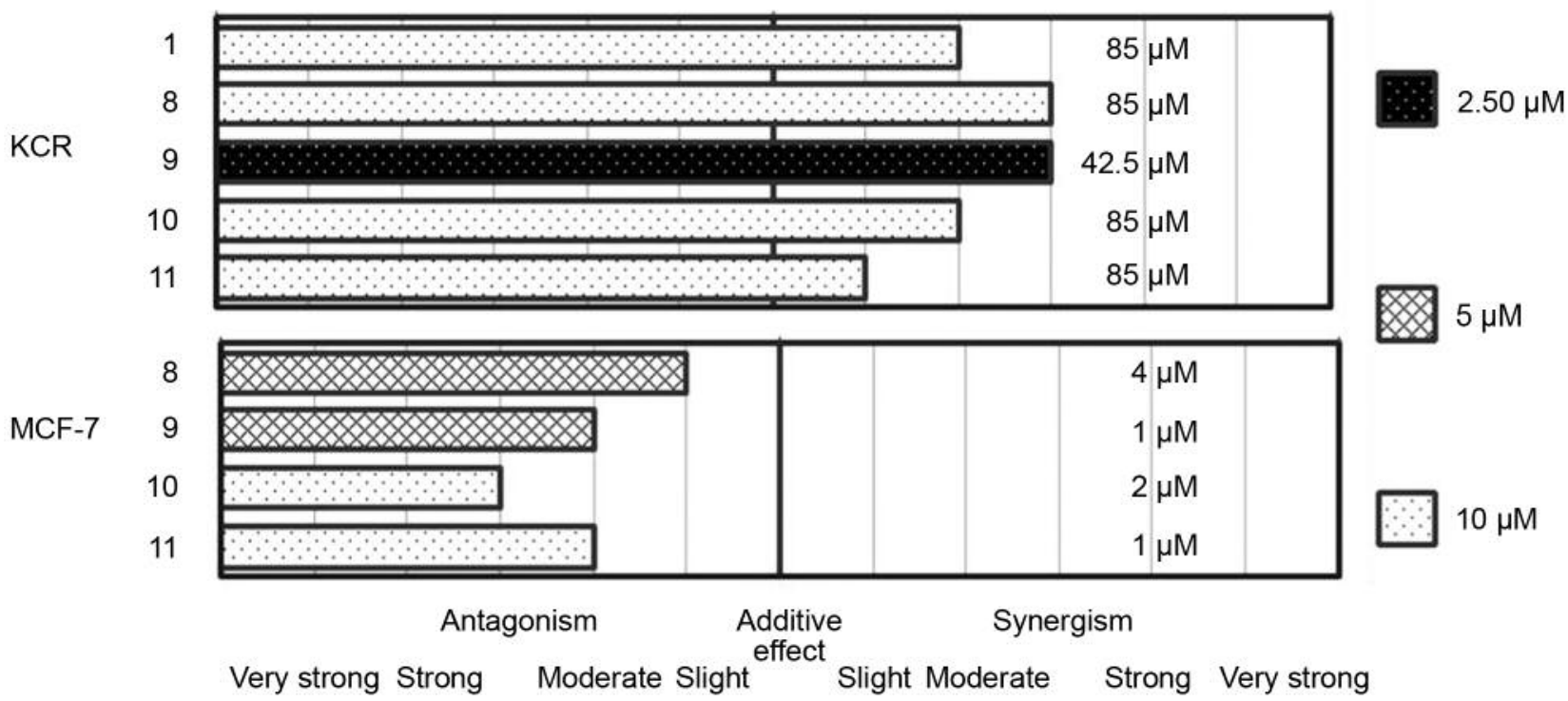

Figure 2. Interactions of the active Se-compounds with doxorubicin in KCR and MCF-7 cells. The figure indicates, at the most effective interaction ratio (doxorubicin:Se-compound), the concentration of the Se-compound in the presence of doxorubicin at the concentration indicated; furthermore the type of interaction (antagonism, additive effect and synergism) is also presented.

their cytotoxicity towards these cell lines. The dilutions of doxorubicin were made in a horizontal direction in $100 \mu$, and the dilutions of the Se-compounds vertically in the microtiter plate in $50 \mu \mathrm{l}$ volume. The plates were incubated for $72 \mathrm{~h}$ at $37^{\circ} \mathrm{C}$ in $5 \%$ $\mathrm{CO}_{2}$ atmosphere. The cell growth rate was determined after MTT staining. At the end of the incubation period, $20 \mu \mathrm{l}$ of MTT (Sigma) solution (from a stock solution of $5 \mathrm{mg} / \mathrm{ml}$ ) were added to each well. After incubation at $37^{\circ} \mathrm{C}$ for $4 \mathrm{~h}, 100 \mu \mathrm{l}$ of SDS (Sigma) solution $(10 \%$ in $0.01 \mathrm{M} \mathrm{HCI})$ were added to each well and the plates were further incubated at $37^{\circ} \mathrm{C}$ overnight. Optical density (OD) was measured at $540 / 630 \mathrm{~nm}$ with Multiscan EX ELISA reader (Thermo Labsystems). Combination index (CI) values at 50\% of the growth inhibition dose (ED50) were determined using CompuSyn software (ComboSyn, Inc., Paramus, NJ, USA) to plot four to five data points at each ratio. CI values were calculated by means of the median-effect equation, according to the Chou-Talalay method, where $\mathrm{CI}<1, \mathrm{CI}=1$, and $\mathrm{CI}>1$ represent synergism, additive effect (or no interaction), and antagonism, respectively $(11,12)$.

Apoptosis induction. The ability of the Se-compounds to induce apoptosis was determined on breast cancer cell lines. The apoptosis assays were performed using Annexin V-FITC Apoptosis Detection Kit from Calbiochem (EMD Biosciences, Inc. La Jolla, CA, USA), following the instructions provided by the manufacturer. This assay enables the quantification of early and late apoptotic events, as well as necrosis and cell death in the cell population exposed to the Secompounds. The density of the cell suspension was adjusted to $1 \times 10^{6}$ cells $/ \mathrm{ml}$. The cell suspension was distributed into $0.5 \mathrm{ml}$ aliquots $\left(5 \times 10^{5}\right.$ cells $)$ to a 24 -well microplate and incubated overnight at $37^{\circ} \mathrm{C}$ in $5 \% \mathrm{CO}_{2}$. On the following day, the medium was removed, and fresh medium was added to the cells. The cells were then incubated in the presence of Se-compounds at $2 \mu \mathrm{M}$ for $3 \mathrm{~h}$ at $37^{\circ} \mathrm{C}$. $12 \mathrm{H}$-Benzo[ $\left.\alpha\right]$ phenothiazine M627 (13), which is a known early apoptosis inducer, was used as positive control. The samples were washed in PBS and fresh medium was added to the cells, followed by the incubation of the plate for $24 \mathrm{~h}$ at $37^{\circ} \mathrm{C}$, in $5 \% \mathrm{CO}_{2}$. After the incubation period, the cells were trypsinized. The harvested cells were centrifuged at $2,000 \times g$ for $2 \mathrm{~min}$. The cells were then re-suspended in fresh serum-free medium. Thereafter, the apoptosis assay was carried out according to the rapid protocol of the kit and the fluorescence was analyzed immediately using a ParTec CyFlow flow cytometer (Partec, Münster, Germany).

\section{Results}

The screening of the anticancer activity of Se-compounds in MCF-7 cells indicated that selenoanhydride $\mathbf{1}$ and selenoesters 2-7 were not cytotoxic towards this cell line (Table I), as all the $\mathrm{IC}_{50}$ values of these derivatives were above $100 \mu \mathrm{M}$. In contrast, the ketone-containing selenoesters 9-11 had a potent low-micromolar activity, as their $\mathrm{IC}_{50}$ values ranged from 1.04 to $1.70 \mu \mathrm{M}$, whereas the $\mathrm{IC}_{50}$ of the phenoxycarbonylmethyl selenoester 7 was $64.8 \mu \mathrm{M}$. Results were similar for the multidrug-resistant KCR cells except for two derivatives. Firstly, in this case the $\mathrm{IC}_{50}$ of selenoanhydride $\mathbf{1}$, at a concentration as low as $2.35 \mu \mathrm{M}$, which was more than 40 -fold lower than for MCF-7, suggesting that this compound acts directly on ABCB1 overexpressed by KCR cells. Secondly, compound $\mathbf{1 1}$ was close to 2-fold less active against KCR cells compared to MCF-7 cells. None of compounds 12-15 
Table I. Cytotoxic activity of Se-compounds against MCF-7 and doxorubicin-resistant KCR breast cancer cell lines.

\begin{tabular}{|c|c|c|c|c|c|c|c|c|c|}
\hline \multirow[t]{2}{*}{ Compound } & \multicolumn{2}{|c|}{ MCF-7 } & \multicolumn{2}{|c|}{ KCR } & \multirow{2}{*}{$\begin{array}{c}\text { SI MCF-7 } \\
\text { /KCR }\end{array}$} & \multicolumn{2}{|c|}{ MRC-5* } & \multicolumn{2}{|c|}{ SI } \\
\hline & $\mathrm{IC}_{50}(\mu \mathrm{M})$ & $\pm \mathrm{SD}$ & $\mathrm{IC}_{50}(\mu \mathrm{M})$ & $\pm \mathrm{SD}$ & & $\mathrm{IC}_{50}(\mu \mathrm{M})$ & $\pm \mathrm{SD}$ & MRC-5/MCF-7 & MRC-5/KCR \\
\hline 1 & $>100$ & - & 2.35 & 0.47 & $\geq 42$ & $>100$ & - & - & $\geq 42$ \\
\hline 2 & $>100$ & - & $>100$ & - & - & 4.26 & 0.65 & $\leq 0.04$ & $\leq 0.04$ \\
\hline 3 & $>100$ & - & $>100$ & - & - & 17.9 & 0.00 & $\leq 0.18$ & $\leq 0.18$ \\
\hline 4 & $>100$ & - & $>100$ & - & - & 28.4 & 0.70 & $\leq 0.28$ & $\leq 0.28$ \\
\hline 5 & $>100$ & - & $>100$ & - & - & 61.5 & 2.16 & $\leq 0.62$ & $\leq 0.62$ \\
\hline 6 & $>100$ & - & $>100$ & - & - & 76.6 & 0.92 & $\leq 0.77$ & $\leq 0.77$ \\
\hline 7 & $>100$ & - & $>100$ & - & - & 33.4 & 3.08 & $\leq 0.33$ & $\leq 0.33$ \\
\hline 8 & 64.8 & 16.7 & 82.2 & 15.7 & 0.79 & $>100$ & - & $\geq 1.5$ & $\geq 1.2$ \\
\hline 9 & 1.04 & 0.47 & 0.96 & 0.18 & 1.08 & 5.35 & 0.24 & 5.2 & 5.6 \\
\hline 10 & 1.70 & 0.45 & 1.75 & 0.15 & 0.97 & 8.10 & 0.90 & 4.8 & 4.6 \\
\hline 11 & 1.45 & 0.23 & 2.37 & 0.30 & 0.61 & 5.04 & 0.71 & 3.5 & 2.2 \\
\hline
\end{tabular}

$\mathrm{IC}_{50}: 50 \%$ Inhibitory concentration; SI: selectivity index. For cytoxicity, $\mathrm{IC}_{50}$ values in bold denote $\mathrm{IC}_{50}$ values below $5 \mu \mathrm{M}$, and those in italics, values between 5 and $10 \mu \mathrm{M}$. In selectivity, values in bold denote a strong selectivity, and in italics, a moderate selectivity. Compounds 12-15 were not included as their $\mathrm{IC}_{50}$ values for the three cell lines were above $100 \mu \mathrm{M}$. *Values taken from a previous study (6).

evaluated for comparison studies exerted cytotoxic effects at concentrations below $100 \mu \mathrm{M}$ on any of KCR, MCF-7 and MRC-5 cell lines evaluated. The anticancer effect of Secompounds on MRC-5 was determined previously (6).

Regarding the selectivity of the selenoesters towards cancer cells, it was clearly observed that the ketonecontaining selenoesters exerted a moderate selectivity towards MCF-7 and KCR cancer cells with respect to the non-tumorous MRC-5 lung fibroblast cells (6), with the exception of compound 11, which was slightly selective towards KCR, exhibiting a SI of 2.2. The SI of compound 9 for KCR cells was approximately to $6(\mathrm{SI}=5.6)$, which was the threshold for considering that a compound is strongly selective. Remaining selenoesters lacked of selectivity due to their poor activity against MCF-7 and KCR.

In contrast, selenoanhydride (1) was strongly selective towards KCR cells in comparison to the non-tumorous fibroblast cells with SI of 42 (7-fold higher the threshold).

The five active compounds in the cytotoxicity assay were evaluated in combination with doxorubicin (Figure 2). Results were quite fascinating as they showed a marked difference between the two tested cell lines. All Secompounds assayed exerted synergistic interactions with doxorubicin against the KCR cell line, whereas all the observed interactions of the selenoesters with doxorubicin against the MCF-7 cell line were antagonistic.

Against KCR cells, compound 9 was undoubtedly the most profitable in the combination assay, as it showed the highest grade of synergy among all evaluated compounds and at the lowest concentrations of both Se-compound $(2.5 \mu \mathrm{M})$ and doxorubicin $(42.5 \mu \mathrm{M})$. The remaining Se-compounds interacted in a synergistic manner with doxorubicin at a concentration of compound and drug four- and two-fold higher, respectively. Against MCF-7 cells, compound 9 interacted in a moderately antagonistic manner at higher concentration $(5 \mu \mathrm{M})$. Slight antagonism was observed for compound $\mathbf{8}$ at the same concentration, but the concentration of doxorubicin was in this case four times higher.

Finally, the compounds were not able to induce significant apoptotic events in MCF-7 and KCR cells; with the exception of the phenoxycarbonylmethyl selenoester $\mathbf{7}$ in MCF-7 cells. This derivative, at a low concentration $(2 \mu \mathrm{M})$, triggered early apoptotic and late apoptotic/necrotic events in $16.9 \%$ and $7.85 \%$ of cells (Figure 3). This apoptosisinducing activity was moderate, as reference compound M627 induced $20.8 \%$ and $67.1 \%$ events, respectively.

\section{Discussion}

Conventional chemotherapy in the treatment of early and metastatic breast cancer is partly based on the administration of anthracycline drugs e.g. doxorubicin. Since these drugs provoke side-effects such as cardiotoxicity and myelosuppression $(14,15)$, there is an urgent need to minimize the side-effects. In order to reduce the adverse effect of anthracyclines, several alternatives could be applied, for example the use of liposomal doxorubicin (16), nanotechnology (17) and preparation of less toxic derivatives.

In this study, we investigated the cytotoxic properties of Se-compounds and their interaction with doxorubicin in order to find effective adjuvants for combination chemotherapy using doxorubicin with Se-compounds.

As commented in the previous section, selenoanhydride $\mathbf{1}$ exerted selective activity towards the resistant KCR cell line overexpressing $\mathrm{ABCB} 1 \quad\left(\mathrm{IC}_{50}=2.35 \mu \mathrm{M}\right)$, as it was 


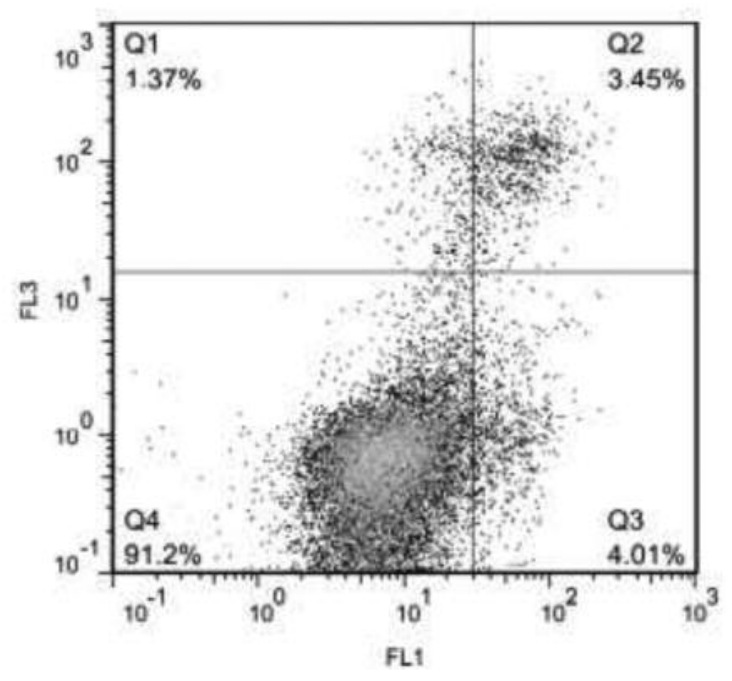

Untreated control

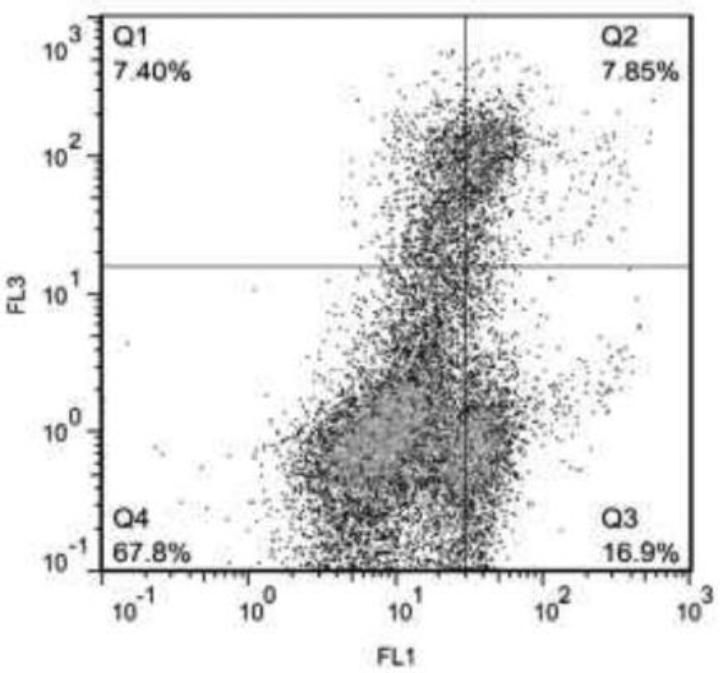

Compound $7(2 \mu \mathrm{M})$

ineffective against MCF-7 and MRC-5 (non-tumor lung fibroblast) cells. These results are in accordance with our previous data confirming that selenoanhydride $\mathbf{1}$ interacts directly with $\mathrm{ABCB} 1(5,6)$. Surprisingly, this derivative was unable to trigger apoptotic events in the tested breast cancer cell lines, probably due to a dual inhibition of $\mathrm{ABCB} 1$ and multidrug resistance protein 1 efflux pumps, however, other resistance mechanisms are also involved.

Among the selenoesters, only the ketone-containing selenoesters 9-11 exerted significant cytotoxic activity against these two cell lines. Symmetrical dimethyl selenodiesters 2-

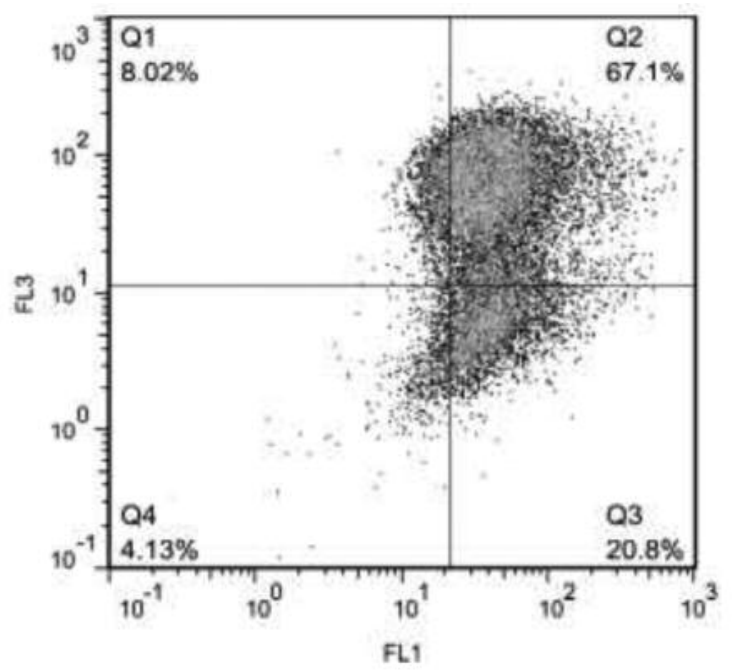

$12 H$-[a]benzophenothiazine $(20 \mu \mathrm{M})$
Figure 3. Apoptosis induction by compound 7 in MCF-7 cells compared to the positive control 12H-[a]benzophenothiazine. Q1: dead cells; Q2: cells undergoing late apoptosis/necrosis; Q3: cells undergoing early apoptosis; Q4: healthy, living cells.
5 were inactive, as were the amide-containing selenoester 6 and the methoxycarbonylmethyl selenoester 7. In the latter, the replacement of the methyl moiety bound to the oxygen of the $O$-ester by a phenyl ring lowers the $\mathrm{IC}_{50}$ but still at a level between 60 and $100 \mu \mathrm{M}$. When this phenyl ester is replaced by a methylketone (9) or a tert-butylketone, then the activity increases dramatically, this time lowering the $\mathrm{IC}_{50}$ to low micromolar concentrations, pointing to the crucial role of this alkylketone moiety in the biological activity of ketonecontaining selenoesters. Furthermore, these promising selenium derivatives exerted a noteworthy selectivity towards 
the evaluated cancer cells (MCF-7, KCR) rather than the nontumorous cell line MRC-5.

The results observed in combination assays are astonishing, in that they point to differential activity in the two cell lines, the resistant (KCR) one in this case being more sensitive to the action of the compounds. It has been shown that doxorubicin and methylseleninic acid act synergistically on MCF-7 cells, inducing apoptosis because doxorubicin and selenium cooperatively activate first apoptosis signal (FAS) pathway. Doxorubicin causes Fas oligomerization in a FasLindependent manner and methylseleninic acid increases FASassociated death domain protein expression together triggering apoptosis (18). Out of our 11 Se-compounds, only methoxycarbonylmethyl $p$-chlorobenzoselenoate (7) induced apoptosis of MCF-7 cells, the other derivatives were not capable of provoking apoptosis of MCF-7 and KCR cells.

This is very relevant as it suggests that these derivatives might have the ability to overcome some aspects of resistance of KCR cells. Since the derivatives are proven ABCB1 modulators, their synergism with doxorubicin might be due to their interaction with this efflux pump overexpressed by KCR cells. On the contrary, the explanation of their antagonism with doxorubicin in MCF-7 cells is the involvement of other resistance mechanisms and cellular processes. This could open a new and straightforward approach to treat ABCB1expressing resistant breast cancer that is resistant to the treatments currently in clinical use. The methylketone selenoester 9 would be in such cases the most promising compound. Its activity makes it worth investigating in more depth for potential applications of this compound and of closely related new derivatives (which could be synthesized in future work) with intrinsic anticancer activity as sensitizers of resistant cancer.

Overall, the results obtained herein highlight the importance for biological activity of the $-\mathrm{COSeCH}_{2} \mathrm{COCH}_{3}$ and $\mathrm{COSeCH}_{2} \mathrm{CO}\left(\mathrm{CH}_{3}\right)_{3}$ moieties in comparison with the remaining substituents considered (- $\mathrm{COSeCH}_{3},-\mathrm{COSeCH}_{2} \mathrm{CO}$ $\mathrm{NH}_{2},-\mathrm{COSeCH}_{2} \mathrm{COOCH}_{3}$, and $-\mathrm{COSeCH}_{2} \mathrm{COPh}$ ). The good cytotoxic activity, selectivity and ability to modulate the effect of doxorubicin found for the ketone-containing selenoesters 9-11 against the two breast cancer cell lines evaluated are in agreement with previous work of our group on mouse Tlymphoma cells and colonic adenocarcinoma cells $(5,6)$ and draw the attention to this privileged moiety. In future studies it will be necessary to obtain and evaluate more compounds with these moieties in order to ascertain what substituents in the phenyl ring bound to the carbonyl of the selenoester enhance activity, with the aim of designing more potent and selective anticancer agents.

\section{Conflicts of Interest}

The Authors declare no conflicts of interest in regard to this study.

\section{Authors' Contributions}

Enrique Domínguez-Álvarez synthesized the compounds evaluated and wrote the article. Carmen Sanmartín synthesized the compounds evaluated. Gabriella Spengler conceived the experiments and wrote the article. Andrea Csonka, Annamária Kincses, Márta Nové and Zsófia Vadas performed the biological experiments.

\section{Acknowledgements}

The study was also supported by the grant EFOP 3.6.3-VEKOP-162017-00009 of the Ministry of Human Capacities of the Government of Hungary. Gabriella Spengler was supported by the János Bolyai Research Scholarship of the Hungarian Academy of Sciences. Enrique Domínguez-Álvarez had financial support from the Consejo Superior de Investigaciones Científicas (Grant 201780I027). Carmen Sanmartín was funded by Uned Pamplona, by Fundación Bancaria "La Caixa" and by Fundación Caja Navarra.

\section{References}

1 Gandin V, Khalkar P, Braude J and Fernandes AP: Organic selenium compounds as potential chemotherapeutic agents for improved cancer treatment. Free Radic Biol Med 127: 80-97, 2018. PMID: 29746900. DOI: 10.1016/j.freerad biomed.2018.05.001

2 Sanmartín C, Plano D, Sharma AK and Palop JA: Selenium compounds, apoptosis and other types of cell death: an overview for cancer therapy. Int J Mol Sci 13(8): 9649-9672, 2012. PMID: 22949823. DOI: $10.3390 /$ ijms 13089649

3 Álvarez-Pérez M, Ali W, Marć MA, Handzlik J and DomínguezÁlvarez E: Selenides and Diselenides: A review of their anticancer and chemopreventive activity. Molecules 23(3): E628, 2018. PMID: 29534447. DOI: 10.3390/molecules23030628

4 Tan HW, Mo HY, Lau ATY and Xu YM: Selenium species: Current status and potentials in cancer prevention and therapy. Int J Mol Sci 20(1): pii: E75, 2018. PMID: 30585189. DOI: 10.3390/ijms20010075

5 Domínguez-Álvarez E, Gajdács M, Spengler G, Palop JA, Marć MA, Kieć-Kononowicz K, Amaral L, Molnár J, Jacob C, Handzlik J and Sanmartín C: Identification of selenocompounds with promising properties to reverse cancer multidrug resistance. Bioorg Med Chem Lett 26(12): 2821-2824, 2016. PMID: 27156771. DOI: 10.1016/j.bmcl.2016.04.064

6 Gajdács M, Spengler G, Sanmartín C, Marć MA, Handzlik J and Domínguez-Álvarez E: Selenoesters and selenoanhydrides as novel multidrug resistance reversing agents: A confirmation study in a colon cancer MDR cell line. Bioorg Med Chem Lett 27(4): 797802, 2017. PMID: 28126516. DOI: 10.1016/ j.bmcl.2017.01.033

7 Song M, Kumaran MN, Gounder M, Gibbon DG, Nieves-Neira W, Vaidya A, Hellmann M, Kane MP, Buckley B, Shih W, Caffrey PB, Frenkel GD and Rodriguez-Rodriguez L: Phase I trial of selenium plus chemotherapy in gynecologic cancers. Gynecol Oncol 150(3): 478-486, 2018. PMID: 30068487. DOI: 10.1016/j.ygyno.2018.07.001

8 Zakharia Y, Bhattacharya and Rustum YM: Selenium targets resistance biomarkers enhancing efficacy while reducing toxicity of anticancer drugs: Preclinical and clinical development. Oncotarget 9(12): 10765-10783, 2018. PMID: 29535842. DOI: 10.18632 /oncotarget. 24297 
9 Domínguez-Álvarez E, Plano D, Font M, Calvo A, Prior C, Jacob C, Palop JA and Sanmartín C: Synthesis and antiproliferative activity of novel selenoester derivatives. Eur J Med Chem 73: 153-166, 2014. PMID: 24389510. DOI: 10.1016/ j.ejmech.2013.11.034

10 Spengler G, Gajdács M, Marć MA, Domínguez-Álvarez E and Sanmartín C: Organoselenium compounds as novel adjuvants of chemotherapy drugs-a promising approach to fight cancer drug resistance. Molecules 24(2): pii: E336, 2019. PMID: 30669343. DOI: $10.3390 /$ molecules 24020336

11 Chou TC: Theoretical basis, experimental design, and computerized simulation of synergism and antagonism in drug combination studies. Pharmacol Rev 58: 621-681, 2006. PMID: 16968952. DOI: $10.1124 /$ pr.58.3.10

12 Chou TC: Drug combination studies and their synergy quantification using the Chou-Talalay method. Cancer Res 70: 440-446, 2010. PMID: 20068163. DOI: 10.1158/0008-5472. CAN-09-1947

13 Mucsi I, Varga A, Kawase M, Motohashi N and Molnar J: Interaction between various resistance modifiers and apoptosis inducer 12H-benzo[alpha]phenothiazine. Anticancer Res 22(5): 2833-2836, 2002. PMID: 12530005

14 McGowan JV, Chung R, Maulik A, Piotrowska I, Walker JM and Yellon DM: Anthracycline chemotherapy and cardiotoxicity. Cardiovasc Drugs Ther 31(1): 63-75. 2017. PMID: 28185035. DOI: $10.1007 / \mathrm{s} 10557-016-6711-0$
15 Thorn CF, Oshiro C, Marsh S, Hernandez-Boussard T, McLeod H, Klein TE and Altman RB: Doxorubicin pathways: Pharmacodynamics and adverse effects. Pharmacogenet Genomics 21(7): 440-446, 2011. PMID: 21048526. DOI: 10.1097/FPC.0b013e $32833 \mathrm{ffb} 56$

16 Lao J, Madani J, Puértolas T, Alvarez M, Hernández A, Pazo-Cid R, Artal A and Antón Torres A: Liposomal doxorubicin in the treatment of breast cancer patients: A review. J Drug Deliv 2013: 456409, 2013. PMID: 23634302. DOI: 10.1155/2013/456409

17 Wu D, Si M, Xue HY and Wong HL: Nanomedicine applications in the treatment of breast cancer: Current state of the art. Int J Nanomedicine 12: 5879-5892, 2017. PMID: 28860754. DOI: 10.2147/IJN.S123437

$18 \mathrm{Li} \mathrm{S}$, Zhou Y, Dong Y and Ip C: Doxorubicin and selenium cooperatively induce FAS signaling in the absence of FAS/FAS ligand interaction. Anticancer Res 27(5A): 3075-82, 2007. PMID: 17970047.
Received April 9, 2019

Revised May 8, 2019

Accepted May 13, 2019 